\title{
Falls requiring medical attention among veterans with multiple sclerosis: A cohort study
}

\author{
Michelle H. Cameron, MD, PT; ${ }^{*}$ Amy J. Poel, MPH, PhC; ${ }^{2-3}$ Jodie K. Haselkorn, MD, MPH; $;^{2,4}$ Alex Linke, BS; ${ }^{5}$ \\ Dennis Bourdette, $\mathbf{M D}^{1}$ \\ ${ }^{1}$ Neurology Service and Multiple Sclerosis Center of Excellence-West, Portland Department of Veterans Affairs (VA) \\ Medical Center (VAMC) and Department of Neurology, Oregon Health \& Science University, Portland, OR; ${ }^{2}$ Multiple \\ Sclerosis Center of Excellence-West, VA Puget Sound Health Care System, Seattle, WA; Departments of \\ ${ }^{3}$ Epidemiology and ${ }^{4}$ Rehabilitation Medicine, University of Washington, Seattle, WA; ${ }^{5}$ Behavioral Health \& Clinical \\ Neurosciences Division, Portland VAMC, Portland, OR
}

\begin{abstract}
The purpose of this study was to estimate the relative risk of an injurious fall requiring medical attention in veterans with multiple sclerosis (MS) compared with veterans without MS after controlling for sex, age, and healthcare use. The sample included 195,417 veterans treated at Veterans Health Administration (VHA) facilities in the Northwest United States in fiscal year 2008. We obtained information regarding MS diagnosis, injurious falls (operationalized as International Classification of Diseases-9th Revision-Clinical Modification codes E880-E888), and demographic and healthcare use data from the VHA Consumer Health Information Performance Set database. Using logistic regression, we determined the adjusted odds ratio (OR) of an injurious fall to be three times higher in female veterans with MS than in female veterans without MS $(\mathrm{OR}=3.0$, $95 \%$ confidence interval $[\mathrm{CI}]=1.6-5.5$ ). The adjusted OR of an injurious fall for men with MS was also higher than for men without MS, but this difference was not statistically significant $(\mathrm{OR}=1.2,95 \% \mathrm{CI}=0.8-2.1)$. We recommend further studies evaluating the medical, social, and economic consequences of injurious falls, as well as interventions to prevent injurious falls, to improve the independence and quality of life of veterans and others living with MS.
\end{abstract}

Key words: accidental falls, cohort study, disability, epidemiology, medical records, multiple sclerosis, risk, sex, veterans, wounds and injuries.

\section{INTRODUCTION}

Multiple sclerosis (MS) is a chronic progressive disease and the most common neurologic disease of young adults. By conservative estimates, 400,000 people live with MS in the United States today [1] and over 2.5 million people live with MS worldwide [2]. Each year, approximately 16,000 veterans with MS receive healthcare services from the Veterans Health Administration (VHA). About 6,000 of these veterans are considered to have a service-connected disability for MS because they acquired it or showed related symptoms during their military service.

Abbreviations: CHIPS $=$ Consumer Health Information Performance Set, CI = confidence interval, FY = fiscal year, ICD-9$\mathrm{CM}=$ International Classification of Diseases-9th RevisionClinical Modification, $\mathrm{MS}=$ multiple sclerosis, $\mathrm{OR}=$ odds ratio, VA $=$ Department of Veterans Affairs, VHA = Veterans Health Administration, VISN $20=$ Veterans Integrated Service Network 20.

* Address all correspondence to Michelle $\mathrm{H}$. Cameron, MD, PT; Department of Neurology, Oregon Health \& Science University, 3181 SW Sam Jackson Park Rd, CR120, Portland, OR 97239; 503-418-1971; fax: 503-494-7289.

Email: cameromi@ohsu.edu

DOI:10.1682/JRRD.2009.12.0192 
Based on data from the early 1990s, the VHA spends approximately $\$ 274$ million each year treating veterans with MS at an average cost of $\$ 20,000$ per patient per year [3].

Existing research indicates that people with MS fall frequently [4-6], likely more than the general population [7-9], and more than the elderly, a group in which fall risk [10-11] and its effects are well studied and characterized [12-18]. A few studies have attempted to ascertain how often people with MS fall, but no comparisons with other groups have been reported. A cross-sectional study in Italy found that 54 percent $(27 / 50)$ of their small sample of subjects reported falling at least once and 32 percent (16/50) reported falling twice or more within the previous 2 months [4]. Similarly, another larger cross-sectional study of falls among people with MS aged 45 to 90 years in the United States $(n=1,089)$ found that 52 percent of subjects reported falling at least once in the previous 6 months [5]. Most recently, the first prospective study of falls among people with MS found that 63 percent of the subjects (48/76) recorded at least one fall and 58 percent (44/76) recorded two or more falls over a 3 month period [6]. Research on the frequency of falls in people with MS has drawn attention to this important issue but has been limited by crosssectional design, selection and recall bias, and small sample size, as well as a lack of comparison groups.

Only one published cross-sectional study has examined the incidence of injurious falls in people with MS. Peterson et al. found that, of 354 people with MS aged 55 to 94 years in the United States, more than 50 percent reported receiving medical care for a fall-related injury at least once and 12 percent reported receiving medical care for a fall-related injury in the 6 months before the interview [19]. This potential for fall-related injuries likely contributes to loss of independence (mobility and activities of daily living) as well as reduced length [20] and quality of life [5] for people with MS.

Despite falls having been long recognized as common in people with MS [4-6] and the significant potential effect of falls for people with MS [19,21], the risk factors are not well understood. Falls in people with MS have been found to be associated with being male [5-6], impaired balance [4-6], reduced ability to walk [4-6,22], and use of a cane [4] or other walking aid [6]. In addition, studies have identified disturbed proprioception $[6,22]$, spasticity [5,22], and more severe MS (higher Expanded Disability Status Scale scores) [6] as risk factors for falls. People with MS also report that divided attention, reduced muscular endurance, fatigue, and heat sensitivity can cause them to fall [22]. Establishing whether individuals with MS have more injurious falls than other groups and identifying high-risk groups with MS is essential to developing effective and meaningful interventions.

Although previously published studies indicate that falls and injurious falls are common in people with MS, none has evaluated falls or injurious falls specifically in veterans with MS. Veterans with MS are an important group in VHA. MS most commonly first presents in early adulthood and is often diagnosed during military service or soon after. Veterans with MS are frequently considered to have MS as a service-connected disability and are often followed by the VHA from the time of diagnosis through end of life. The VHA has a long-standing commitment to providing medical, surgical, and rehabilitation interventions to optimize the health status, activities, and social participation of veterans with MS. In 2003, the Department of Veterans Affairs (VA) funded two MS Centers of Excellence to promote clinical services, education, information, and research involving veterans with MS. Evidence about falls and injurious falls in veterans with MS is lacking and more data is necessary to consider whether targeted interventions and educational programs are warranted.

VHA health services databases are well suited to studying injurious falls in veterans with MS. These databases have been used to study fall frequency and fall risk factors in older veterans [23-24]. Analyzing existing data on a cohort of veterans with and without MS is a logical strategy for developing an evidence base for injurious falls that require medical attention among veterans who use VHA. This strategy can also contribute to the overall literature on falls in people with MS by including a comparison group. An existing database allows efficient assembly of a retrospective cohort to determine the cumulative incidence of injurious falls in the groups with and without MS. Including records from all veterans who received care in a studied geographic region also minimizes selection bias and including only recorded injurious falls that require medical attention may minimize recall bias.

The purpose of this study was to estimate the relative risk of an injurious fall requiring medical attention in veterans with MS compared with veterans without MS after adjusting for sex, age, and healthcare use. Our hypothesis was that, in 2008, after adjusting for sex, age, and number of clinic visits, more veterans with MS than veterans without MS had an injurious fall that required medical attention at the VHA. 


\section{METHODS}

We obtained all data from the VHA Consumer Health Information and Performance Set (CHIPS). This database includes demographic, diagnostic, and healthcare use information derived from electronic medical records of all veterans who receive medical care at Veterans Integrated Service Network 20 (VISN 20) facilities [25]. To be included in this study, the veteran had to be receiving healthcare at a VISN 20 facility. This was operationalized as having at least two outpatient visits at a VISN 20 healthcare facility in fiscal year (FY) 2008 (October 1, 2007September 31, 2008) recorded in CHIPS. CHIPS is particularly suited to studying veterans with MS because the entire catchment area of VISN 20 is above the $40^{\circ}$ latitude and, although MS occurs throughout the world, it is most prevalent above the $40^{\circ}$ latitude [26-28]. CHIPS is also well suited to a study of injurious falls requiring medical attention in VHA users with MS because it is a relational database and includes diagnostic codes for both MS and injurious falls.

We defined the exposure of interest (independent variable) as having an International Classification of Diseases-9th Revision-Clinical Modification (ICD-9-CM) [29] diagnosis code for MS (code 340) recorded in the CHIPS database in FY2007. To reduce inaccurate ascertainment of MS due to coding errors, we only included individuals in the final target population if they also met at least one of the following criteria at any time: (1) experienced inpatient hospitalization for MS (hospitalization coded with ICD-9-CM diagnosis code 340), (2) received a disease-modifying agent (interferon $\beta 1 \mathrm{a}$, interferon $\beta 1 \mathrm{~b}$, or glatiramer acetate) used only to treat MS, (3) had a serviceconnected disability for MS (diagnosis confirmed through medical review for VA disability pension), or (4) had at least two outpatient encounters where the primary ICD-9CM diagnosis code was 340 and at least one encounter where the primary ICD-9-CM diagnosis code was 340 during each year in which they received some VA medical service from FY2000 to FY2008. This algorithm for identifying an MS target population has been validated in previous work and has been shown to identify and eliminate individuals with or without MS with a high degree of sensitivity and specificity [30].

We defined the outcome of interest (dependent variable) as having an ICD-9-CM diagnosis code for an injurious fall (codes E880-E888) recorded in the CHIPS database in FY2008. The ICD-9-CM uses E-codes to sig- nify external causes of injury and uses codes E880-E888 to specifically signify accidental falls. We operationalized "injurious fall" in a record as having a code E880E888 documented in CHIPS at any time in FY2008.

We used a priori knowledge to model the potential confounders of sex, age, and number of clinic visits based on known relationships between people with MS and injurious falls (Figure). Sex and age are both associated with MS and falls, but neither is on the causal pathway between MS and falls. It is known that more women than men have MS [26,31] and that men with MS report more falls than do women with MS [5-6]. Veterans with MS are also younger than the general VHA population [30,32], and younger people generally fall less than older people [12,14]. We included the number of clinic visits in the model on the causal pathway between MS and falls because veterans with MS may have more clinic visits than veterans without MS, which could result in more record of injurious falls in their medical records, regardless of actual number. Adjusting for number of clinic visits allowed us to ascertain the effect of MS on number of injurious falls above and beyond the effect of number of clinic visits.

We assessed the statistical significance of the relationships between the confounders and injurious falls with MS using the Pearson chi-square test (categorical variables) or an unpaired $t$-test (continuous variables). We modeled age and number of clinic visits as categorical variables using splines. Splines allow for representation of relationships between variables while controlling for residual confounding [33]. We tested for the effect of interactions of age with MS and sex with MS on injurious falls using the Wald test and included the interaction term in the model if $p<0.05$.

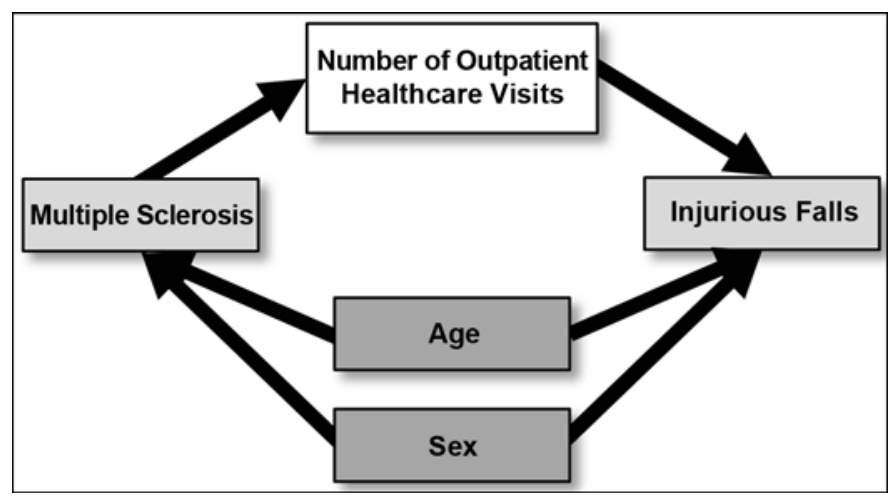

Figure.

A priori model of relationship between exposure (multiple sclerosis) and outcome (injurious falls). 
Table 1.

Characteristics of cohort (FY2008). ${ }^{*}$

\begin{tabular}{|c|c|c|c|c|}
\hline Characteristic & $\begin{array}{c}\text { Total } \\
(n=195,417)\end{array}$ & $\begin{array}{l}\text { With MS } \\
(n=721)\end{array}$ & $\begin{array}{c}\text { Without MS } \\
(n=194,696)\end{array}$ & $p$-Value \\
\hline Sex, $n(\%)$ & & & & $<0.001$ \\
\hline Male & 178,742 (91.5) & 583 (80.9) & 178,159 (91.5) & \\
\hline Female & $16,674(8.5)$ & $138(19.1)$ & 16,536 (8.5) & \\
\hline Data missing & $1(0.0)$ & $0(0.0)$ & $1(0.0)$ & \\
\hline $\mathrm{Age}^{\dagger}$ & & & & $<0.001$ \\
\hline Mean \pm SD (yr) & $60.3 \pm 15.3$ & $57.0 \pm 10.8$ & $60.3 \pm 15.2$ & \\
\hline Median (yr) & 61 & 58 & 61 & \\
\hline Range (yr) & 18-107 & $25-94$ & 18-107 & \\
\hline Data missing $(n)$ & 79 & 0 & 79 & \\
\hline Outpatient Visits $(n)^{\ddagger}$ & & & & $<0.001$ \\
\hline Mean \pm SD & $13.3 \pm 17.8$ & $19.2 \pm 18.6$ & $13.3 \pm 7.7$ & \\
\hline Median & 8 & 14 & 8 & \\
\hline Range & $2-361$ & $2-152$ & $2-361$ & \\
\hline Fall, $n(\%)$ & & & & 0.003 \\
\hline Yes & $2,866(1.5)$ & $20(2.8)$ & $2,846(1.5)$ & \\
\hline No & $192,551(98.5)$ & $701(97.2)$ & 191,850 (98.5) & \\
\hline \multicolumn{5}{|c|}{$\begin{array}{l}\text { Note: Statistical significance assessed using Pearson chi-square for categorical } \\
\text { variables and unpaired } t \text {-test for continuous variables. } \\
{ }^{*} \text { October } 1,2007 \text {-September 31, } 2008 . \\
{ }^{\dagger} \text { Age as of October 1, } 2007 . \\
{ }^{\ddagger} \text { Inclusion criteria included two clinic visits in FY2008. } \\
\text { FY = fiscal year, MS = multiple sclerosis, SD = standard deviation. } \\
\end{array}$} \\
\hline
\end{tabular}

We used logistic regression with robust standard errors to assess the relationship between MS and injurious falls, adjusting for age, sex, number of clinic visits, and significant interactions. We obtained odds ratios (ORs) from the logistic regression. We assessed the fit of the model using the Hosmer-Lemeshow Goodness-of-Fit test. We performed statistical analysis using STATA version 9.2 (StataCorp; College Station, Texas).

\section{RESULTS}

The veteran cohort consisted of 195,417 people. Most of the cohort was male (91.5\%). Of the cohort, 721 met the criteria for a diagnosis of MS (583 men and 138 women). MS was 2.5 times more common in the women than the men $(95 \%$ confidence interval $[\mathrm{CI}]=$ 2.1-3.1, $p<0.001)$. The age of the cohort was $60.3 \pm$ 15.3 years (mean \pm standard deviation unless otherwise specified). Those with MS were younger (57.0 \pm 10.8 vs $60.3 \pm 15.2$ years, $p<0.001)$ and had more outpatient visits $(19.2 \pm 18.6$ vs $13.3 \pm 17.7, p<0.001)$ than those without MS. Of the 721 veterans with MS and 194,696 veterans without MS, only 20 (2.8\%) and 2,846 (1.5\%), respectively, met the criteria for having an injurious fall (Table 1).

A crude association between MS and injurious falls existed before adjustment and inclusion of interaction terms. The unadjusted data suggest that veterans with MS are 1.9 times more likely to sustain an injurious fall than veterans without MS. We found a statistically significant interaction between sex and MS on injurious falls, indicating that the relationship between MS and injurious falls is different for males than for females. Therefore, we determined the OR for injurious falls for both male and female veterans and reported them separately. The interaction between age and MS was not statistically significant.

The final model included adjustments for sex, age, number of clinic visits, and the interaction between sex and MS. The OR for an injurious fall for women with MS compared with women without MS, controlling for age and number of clinic visits, was statistically significant (OR = 3.0, 95\% CI = 1.6-5.5 [Table 2]). The odds for an injurious fall for men with MS was also higher than for men without MS, but this difference was not statistically significant (OR $=1.2$, 95\% CI $=0.8-2.1$ [Table 2]). Because falling was a rare event in this cohort study, the OR obtained from the logistic model approximates the relative risk [34-35]. The resulting outcomes are therefore discussed as the more intuitive outcome (relative risk). The Hosmer-Lemeshow Goodness-of-Fit test $\left(\chi^{2}(d f=8)=9.65, p=0.30\right)$ indicated that this model should not be rejected.

\section{DISCUSSION}

This is the first population-based study to compare the risk of injurious falls in veterans with MS with the risk of injurious falls in veterans without MS. The effect of MS on injurious fall risk was different for male veterans versus female veterans. The risk of an injurious fall was three times higher for female veterans with MS than for female veterans without MS after controlling for age and number of clinic visits. This relationship was statistically significant. Although the direction of the relationship was the same for male veterans with MS compared with male veterans without MS (OR = 1.2), this relationship was not statistically significant.

The increased risk of injurious falls in female veterans with MS compared with female veterans without MS found in this study is consistent with the high incidence of falls [4-6] and injurious falls [19] previously reported 
Table 2.

Risk of recorded falls for veterans with multiple sclerosis (MS) compared with veterans without MS.

\begin{tabular}{|c|c|c|c|c|c|c|c|}
\hline Characteristic & OR & $95 \%$ CI & $n^{*}$ & B & SE & $p$-Value & $\chi^{2}(d f=1)$ \\
\hline Unadjusted: Total & 1.9 & $1.2-3.0$ & 195,417 & 0.64 & 0.23 & $<0.05$ & 37.2 \\
\hline Adjusted: Female ${ }^{\dagger}$ & 3.0 & $1.6-5.5$ & 16,669 & 1.10 & 0.32 & $<0.05$ & 41.8 \\
\hline Adjusted: Male $^{\dagger}$ & 1.2 & $0.8-2.1$ & 178,669 & 0.18 & 0.21 & 0.12 & 27.3 \\
\hline
\end{tabular}

* Of veterans, 79 were excluded from final model because their ages were not available.

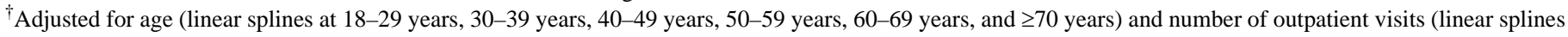
at 2, 3-7, 8-15, and $\geq 16$ ).

$\mathrm{CI}=$ confidence interval, $\mathrm{OR}=$ odds ratio, $\mathrm{SE}=$ standard error.

in people with MS. However, the statistically significant increased relative risk of injurious falls for female, but not male, veterans with MS compared with female and male veterans without MS may appear to contradict the previous findings of male sex being a risk factor for falls [5-6] but sex not affecting the risk for injurious falls [19] in people with MS. This apparent contradiction is likely because our study, which compares injurious fall risk in a group with MS with injurious fall risk in a group without MS, is different from the previous studies that evaluated fall risk and risk factors only in people with MS rather than comparing them with people without MS. Our study does not compare women with MS and men with MS with each other, but rather compares women and men with MS with women and men without MS.

There are a number of possible explanations for the sex difference observed in our study. Female veterans with MS may be less disabled and therefore more mobile and at greater risk for falls than male veterans with MS. Unfortunately, the CHIPS database used in this study did not allow us to evaluate the potentially highly influential effects of level of disability and mobility. It is known that men with MS are typically more disabled than women with MS [36], that the VHA cares for people with MS with higher average disability than in the general community [32], that high levels of disability often reduce mobility, and that people with very limited mobility fall less frequently [37]. Thus, many male veterans with MS who receive their medical care from the VHA may have such limited mobility that on average they do not, as a group, fall significantly more than male veterans without MS, whereas the female veterans with MS may be more mobile and thus fall more than female veterans without MS.

It is also possible that the sex difference we found in the relative risk for injurious falls by veterans with MS compared with veterans without MS does not reflect a true difference in relative risk but rather a difference in ascertainment. It is likely that providers do not ask about falls in a consistent manner since there is no clinical reminder to ask about them. It is possible that female veterans with MS report their falls or are asked about falls by their providers more than female veterans without MS, whereas male veterans with MS do not report falls or are not asked about falls as often as male veterans without MS. This could result in different proportions of the true number of injurious falls being coded in the medical record for men and women. Our method did not allow us to determine how many falls occurred but were not recorded in any of the groups of subjects, but we do know that the number of people with MS sustaining injurious falls captured in our study (2.8\% percent of the study population [Table 1]), was much lower than a previously published estimate of injurious falls among adults with MS where 50 percent of the sample reported having received medical care for a fall-related injury at some time and 12 percent of the sample reported receiving medical care for a fall-related injury in the previous 6 months [19]. Our likely underestimation of number of injurious falls was probably in part because many injurious falls do not come to medical attention and also in part because many of the falls that do come to medical attention are not captured with an E880-E888 ICD-9-CM code in the medical record [38-40]. We do not know whether there are differences between men and women, or between those with and without MS, in ascertainment of falls by this method. However, previous research using VHA outpatient fallrelated E-codes to estimate fall frequency did find that when E-codes were assigned, there was a fall noted in the medical record supporting the specificity of this measure $[23,41]$. It is also possible that the low number of falls we captured using the administrative data of the CHIPS database is accurate and that veterans who receive medical care through the VHA, including those with MS, sustain fewer injurious falls than other people because they have 
more ready access to fall-prevention interventions including healthcare use and necessary durable medical equipment, such as assistive devices for gait and home safety.

This study has a number of strengths. We minimized selection bias because the subjects were not limited to people volunteering for a study on falls or participating in a specialized MS clinic. We also minimized recall bias by using medical records rather than self-report. The complete enumeration of participants yielded an accurate cumulative incidence of recorded injurious falls in the studied population. We also used an a priori model, based on the literature and the known relationships between variables, to statistically evaluate the relative risk of falls associated with MS.

This study also has certain limitations. It may have limited generalizability to veterans who use VHA services in other regions, to veterans who seek healthcare in the private sector, and to the general population. It is known that more veterans in the Northwest (VISN 20) are female and more are younger ( $<65$ years) than is typical for veterans in the rest of the United States [42]. Nationally, on average, veterans are also older (mean age 57.4 vs 35.3 years) and more likely to be male (92\% vs 49.1\%) than the general U.S. population [43] and than the typical population of people with MS. However, we controlled for both age and sex in this study. In addition, in FY2008, approximately 22 percent of veterans received healthcare from the VHA [44] and in the VISN 20 catchment area approximately 19 percent received healthcare from the VHA [45]. Veterans not only have different access to healthcare than the general population but may also have other unique characteristics that we did not control for and that could limit the generalizability of this study to the general population. Furthermore, we did not assess the effects of other known and unknown confounders, including comorbidity, severity of MS, MS subtype, severity of injurious falls, level of activity and participation, home location, level of social support, and availability and use of assistive technology. Given these limitations, the results of this study should be extrapolated with caution.

Despite these limitations, this study does suggest that female veterans with MS sustain more injurious falls than female veterans without MS. This contributes to the existing evidence on falls in people with MS and further supports the need for studies directed at reducing the frequency of injurious falls in this population.

\section{CONCLUSIONS}

This study indicates that female veterans with MS have a statistically significant threefold higher risk for an injurious fall than female veterans without MS. It supports screening for fall risk in all veterans with MS, especially female veterans. This study also raises questions about the risk factors, causes, and outcomes of falls in veterans with MS and supports the need for further research on falls in people with MS.

\section{ACKNOWLEDGMENTS}

\section{Author Contributions:}

Study concept and design: M. H. Cameron, J. K. Haselkorn, D. Bourdette.

Analysis and interpretation of data: A. J. Poel.

Drafting of manuscript: M. H. Cameron, J. K. Haselkorn, A. J. Poel. Critical revision of manuscript for important intellectual content: M. H. Cameron, J. K. Haselkorn, A. J. Poel, D. Bourdette.

Statistical analysis: A. Linke.

Study supervision: M. H. Cameron.

Financial Disclosures: The authors have declared that no competing interests exist.

Funding/Support: This material was based on work supported by a Sylvia Lawry Physician Fellowship from the National Multiple Sclerosis Society and by a Career Development Award (Dr. Cameron) from the VA Rehabilitation Research and Development Service.

Institutional Review: The Portland VA Medical Center institutional review board approved this study.

\section{REFERENCES}

1. Epidemiology of MS [Internet]. New York (NY): National Multiple Sclerosis Society; 2008 [cited 2008 Nov 21]. Available from: http://www.nationalmssociety.org/aboutmultiple-sclerosis/what-we-know-about-ms/who-gets-ms/ epidemiology-of-ms/index.aspx.

2. Kaplin AI, Williams M. How common are the "common" neurologic disorders? Neurology. 2007;69(4):410-11. [PMID: 17646641] DOI:10.1212/01.wnl.0000278071.91524.4d

3. Bourdette DN, Prochazka AV, Mitchell W, Licari P, Burks J. Health care costs of veterans with multiple sclerosis: Implications for the rehabilitation of MS. VA Multiple Sclerosis Rehabilitation Study Group. Arch Phys Med Rehabil. 1993;74(1):26-31. [PMID: 8420515]

4. Cattaneo D, De Nuzzo C, Fascia T, Macalli M, Pisoni I, Cardini R. Risk of falls in subjects with multiple sclerosis. Arch 
Phys Med Rehabil. 2002;83(6):864-67. [PMID: 12048669] DOI:10.1053/apmr.2002.32825

5. Finlayson ML, Peterson EW, Cho CC. Risk factors for falling among people aged 45 to 90 years with multiple sclerosis. Arch Phys Med Rehabil. 2006;87(9):1274-79.

[PMID: 16935067]

DOI:10.1016/j.apmr.2006.06.002

6. Nilsagård Y, Lundholm C, Denison E, Gunnarsson LG. Predicting accidental falls in people with multiple sclerosis-A longitudinal study. Clin Rehabil. 2009;23(3):259-69.

[PMID: 19218300] DOI:10.1177/0269215508095087

7. Rice DP, MacKenzie EJ, Jones AS. Cost of injury in the United States: A report to Congress. San Francisco (CA): Institute for Health \& Aging, University of California and Injury Prevention Center, The Johns Hopkins University; 1989.

8. Chen LH, Warner M, Fingerhut L, Makuc D. Injury episodes and circumstances: National Health Interview Survey, 1997-2007. Vital Health Stat 10. 2009;(241):1-55. [PMID: 20187342]

9. Anderson RN, Miniño AM, Fingerhut LA, Warner M, Heinen MA. Deaths: Injuries, 2001. Natl Vital Stat Rep. 2004;52(21):1-86. [PMID: 15222463]

10. Hornbrook MC, Stevens VJ, Wingfield DJ, Hollis JF, Greenlick MR, Ory MG. Preventing falls among communitydwelling older persons: Results from a randomized trial. Gerontologist. 1994;34(1):16-23. [PMID: 8150304]

11. Hausdorff JM, Rios DA, Edelberg HK. Gait variability and fall risk in community-living older adults: A 1-year prospective study. Arch Phys Med Rehabil. 2001;82(8):1050-56. [PMID: 11494184] DOI:10.1053/apmr.2001.24893

12. Gillespie LD, Robertson MC, Gillespie WJ, Lamb SE, Gates S, Cumming RG, Rowe BH. Interventions for preventing falls in older people living in the community. Cochrane Database Syst Rev. 2009;(2):CD007146. [PMID: 19370674]

13. Gillespie LD, Gillespie WJ, Robertson MC, Lamb SE, Cumming RG, Rowe BH. Interventions for preventing falls in elderly people. Cochrane Database Syst Rev. 2003;(4): CD000340. [PMID: 14583918]

14. Guideline for the prevention of falls in older persons. American Geriatrics Society, British Geriatrics Society, and American Academy of Orthopaedic Surgeons Panel on Falls Prevention. J Am Geriatr Soc. 2001;49(5):664-72. [PMID: 11380764]

15. Injury prevention \& control: Data \& statistics (WISQARS) [Internet]. Atlanta (GA): Centers for Disease Control and Prevention; 2005 [updated 2010 Mar 4; cited 2010 Mar 10]. Available from: http://www.cdc.gov/injury/wisqars/ index.html.
16. Hu G, Baker SP. Recent increases in fatal and non-fatal injury among people aged 65 years and over in the USA. Inj Prev. 2010;16(1):26-30. [PMID: 20179032] DOI:10.1136/ip.2009.023481

17. Stevens JA, Corso PS, Finkelstein EA, Miller TR. The costs of fatal and non-fatal falls among older adults. Inj Prev. 2006;12(5):290-95. [PMID: 17018668] DOI:10.1136/ip.2005.011015

18. Englander F, Hodson TJ, Terregrossa RA. Economic dimensions of slip and fall injuries. J Forensic Sci. 1996;41(5): 733-46. [PMID: 8789837]

19. Peterson EW, Cho CC, Von Koch L, Finlayson ML. Injurious falls among middle aged and older adults with multiple sclerosis. Arch Phys Med Rehabil. 2008;89(6):1031-37. [PMID: 18503796] DOI:10.1016/j.apmr.2007.10.043

20. Brønnum-Hansen H, Hansen T, Koch-Henriksen N, Stenager E. Fatal accidents among Danes with multiple sclerosis. Mult Scler. 2006;12(3):329-32. [PMID: 16764347] DOI:10.1191/135248506ms1280oa

21. Peterson EW, Cho CC, Finlayson ML. Fear of falling and associated activity curtailment among middle aged and older adults with multiple sclerosis. Mult Scler. 2007;13(9): 1168-75. [PMID: 17881391] DOI:10.1177/1352458507079260

22. Nilsagård Y, Denison E, Gunnarsson LG, Boström K. Factors perceived as being related to accidental falls by persons with multiple sclerosis. Disabil Rehabil. 2009;31(16): 1301-10. [PMID: 19479575] DOI:10.1080/09638280802532639

23. Luther SL, French DD, Powell-Cope G, Rubenstein LZ, Campbell R. Using administrative data to track fall-related ambulatory care services in the Veterans Administration Healthcare system. Aging Clin Exp Res. 2005;17(5):412-18. [PMID: 16392417]

24. French DD, Campbell R, Spehar A, Cunningham F, Bulat $\mathrm{T}$, Luther SL. Drugs and falls in community-dwelling older people: A national veterans study. Clin Ther. 2006;28(4): 619-30. [PMID: 16750473]

DOI:10.1016/j.clinthera.2006.04.011

25. Maynard C, Chapko MK. Data resources in the Department of Veterans Affairs. Diabetes Care. 2004;27(Suppl 2):B22-26. [PMID: 15113778]

DOI:10.2337/diacare.27.suppl_2.B22

26. Kurtzke JF, Beebe GW, Norman JE Jr. Epidemiology of multiple sclerosis in U.S. veterans: 1 . Race, sex, and geographic distribution. Neurology. 1979;29(9 Pt 1):1228-35. [PMID: 573402]

27. Dean G. How many people in the world have multiple sclerosis? Neuroepidemiology. 1994;13(1-2):1-7.

[PMID: 8190200] DOI:10.1159/000110351 
28. Weinshenker BG. Epidemiology of multiple sclerosis. Neurol Clin. 1996;14(2):291-308. [PMID: 8827172] DOI:10.1016/S0733-8619(05)70257-7

29. World Health Organization. ICD-9-CM, International Classification of Diseases, Ninth Revision, Clinical Modification, 2009. Los Angeles (CA): Practice Management Information Corporation; 2009.

30. Culpepper WJ 2nd, Ehrmantraut M, Wallin MT, Flannery K, Bradham DD. Veterans Health Administration multiple sclerosis surveillance registry: The problem of case-finding from administrative databases. J Rehabil Res Dev. 2006; 43(1):17-24. [PMID: 16847768] DOI:10.1682/JRRD.2004.09.0122

31. Noonan CW, Williamson DM, Henry JP, Indian R, Lynch SG, Neuberger JS, Schiffer R, Trottier J, Wagner L, Marrie RA. The prevalence of multiple sclerosis in 3 US communities. Prev Chronic Dis. 2010;7(1):A12. [PMID: 20040227]

32. Lo AC, Hadjimichael O, Vollmer TL. Treatment patterns of multiple sclerosis patients: A comparison of veterans and non-veterans using the NARCOMS registry. Mult Scler. 2005;11(1):33-40. [PMID: 15732264] DOI:10.1191/1352458505ms1136oa

33. Greenland S. Dose-response and trend analysis in epidemiology: Alternatives to categorical analysis. Epidemiology. 1995;6(4):356-65. [PMID: 7548341] DOI:10.1097/00001648-199507000-00005

34. Greenland S. Interpretation and choice of effect measures in epidemiologic analyses. Am J Epi. 1987;125(5):761-68. [PMID: 3551588$]$

35. Kleinbaum DG, Klein M. Logistic regression: A self-learning text. 2nd ed. New York (NY): Springer; 2002. p. 11-16.

36. Vollmer TL, Hadjimichael O, Preiningerova J, Ni W, Buenconsejo J. Disability and treatment patterns of multiple sclerosis patients in United States: A comparison of veterans and nonveterans. J Rehabil Res Dev. 2002;39(2):163-74. [PMID: 12051461$]$

37. Studenski S, Duncan PW, Chandler J, Samsa G, Prescott B, Hogue C, Bearon LB. Predicting falls: The role of mobility and nonphysical factors. J Am Geriatr Soc. 1994;42(3): 297-302. [PMID: 8120315]

38. Haga H, Yasumura S, Niino N, Ueno H, Oshima M, Higuchi Y. [An examination of two reporting methods of falls among the elderly living in the community]. Nippon Koshu Eisei Zasshi. 1996;43(11):983-88. Japanese. [PMID: 9033213]

39. Abellera J, Annest JL, Conn JM, Kohn M. How states are collecting and using cause of injury data: 2004 update to the 1997 report [Internet]. Atlanta (GA): Council of State and Territorial Epidemiologists; 2005 [cited 2009 Jul 28]. Available from: http://www.cste.org/pdffiles/newpdffiles/ ECodeFinal3705.pdf.

40. French DD, Campbell R, Spehar A, Cunningham F, Bulat T, Luther SL. Drugs and falls in community-dwelling older people: A national veterans study. Clin Ther. 2006;28(4): 619-30. [PMID: 16750473] DOI:10.1016/j.clinthera.2006.04.011

41. Luther SL, French DD, Powell-Cope G, Rubenstein LZ, Campbell R. Using administrative data to track fall-related ambulatory care services in the Veterans Administration Healthcare system. Aging Clin Exp Res. 2005;17(5):412-18. [PMID: 16392417]

42. Veteran population 2007 [Internet]. Washington (DC): Department of Veterans Affairs; 2008 [updated 2010 Jan 12; cited 2010 Jun 8]. Available from: http://www1.va.gov/ VETDATA/Demographics/Demographics.asp.

43. Richardson C, Waldrop J. Veterans: 2000. Census 2000 brief [Internet]. Washington (DC): U.S. Census Bureau; 2001 [cited 2010 Mar 12]. Available from: http://www.census.gov/ prod/2003pubs/c2kbr-22.pdf.

44. Analysis of unique veterans utilization of VA benefits \& services [Internet]. Washington (DC): Department of Veterans Affairs; 2009 [cited 2010 Mar 12]. Available from: http://www1.va.gov/VETDATA/docs/SpecialReports/ uniqueveteransMay.pdf.

45. VISN 202008 annual report. Washington (DC): Department of Veterans Affairs; 2009 [cited 2009 Sep 15]. Available from:

http://www.visn20.med.va.gov/docs/visn20 annualReport.pdf.

Submitted for publication December 3, 2009. Accepted in revised form August 12, 2010.

This article and any supplementary material should be cited as follows:

Cameron MH, Poel AJ, Haselkorn JK, Linke A, Bourdette D. Falls requiring medical attention among veterans with multiple sclerosis: A cohort study. J Rehabil Res Dev. 2011;48(1):13-20.

DOI:10.1682/JRRD.2009.12.0192

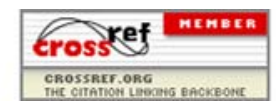

